Boise State University

ScholarWorks

3-4-2008

\title{
Three-Dimensional Structure of Conotoxin tx3a: A m-1 Branch Peptide of the M-Superfamily
}

Owen M. McDougal

Boise State University

Matthew W. Turner

Boise State University

Andrew J. Ormond

Boise State University

C. Dale Poulter

University of Utah 


\title{
Three-Dimensional Structure of Conotoxin tx3a: A m-1 Branch Peptide of the M-Superfamily ${ }^{\dagger}$
}

\author{
Owen M. McDougal ${ }^{*}$, Matthew W. Turner ${ }^{\ddagger}$, Andrew J. Ormond ${ }^{\ddagger}$, and C. Dale Poulter ${ }^{\S}$ \\ *Department of Chemistry and Biochemistry, Boise State University, Boise, Idaho 83725 \\ ${ }^{\S}$ Department of Chemistry, University of Utah, Salt Lake City, Utah 84112
}

\author{
${ }^{*}$ Corresponding author: $\quad$ Owen M. McDougal \\ Boise State University \\ Department of Chemistry and Biochemistry \\ 1910 University Drive, MS 1520 \\ Boise, ID 83725 \\ Phone: 208-426-3964 \\ FAX: 208-426-3027 \\ Email: owenmcdougal@boisestate.edu
}

$\dagger$ This work supported by NIH grants GM 21328, GM 48677, P20 RR016454, and MSTMRI grant \# 6PR3381000154. 


\section{ABSTRACT}

The M-superfamily, one of eight major conotoxin superfamilies found in the venom of the cone snail, contains a Cys framework with disulfide-linked loops labeled 1, 2, and 3 ($\left.C C^{1} C^{2} C^{3} C C-\right)$. M-superfamily conotoxins can be divided into the $m-1,-2,-3$ and -4 branches, based upon the number of residues located in the third Cys loop between the fourth and fifth Cys residues. Here we provide a three-dimensional solution structure for the $\mathrm{m}-1$ conotoxin tx $3 \mathrm{a}$ found in the venom of Conus textile. The 15 amino acid peptide, CCSWDVCDHPSCTCC, has disulfide bonds between $\mathrm{Cys}^{1}$ and $\mathrm{Cys}^{14}, \mathrm{Cys}^{2}$ and $\mathrm{Cys}^{12}$, and $\mathrm{Cys}^{7}$ and $\mathrm{Cys}{ }^{15}$ typical of the C1$\mathrm{C} 5, \mathrm{C} 2-\mathrm{C} 4$, and $\mathrm{C} 3-\mathrm{C} 6$ connectivity pattern seen in $\mathrm{m}-1$ branch peptides. The tertiary structure of tx 3 a was determined by $2 \mathrm{D}^{1} \mathrm{H}$ NMR in combination with the combined assignment and dynamics algorithm for nuclear magnetic resonance (NMR) applications CYANA program. Input for structure calculations consisted of 62 inter- and intraproton, 5 phi angle, and 4 hydrogen bond constraints. The root-mean-square deviation values for the 20 final structures are $0.32+/-0.07 \AA$ and $0.84+/-0.11 \AA$ for the backbone and heavy atoms, respectively. Surprisingly, the structure of tx3a has a "triple-turn" motif seen in the $\mathrm{m}-2$ branch conotoxin mr3a, which is absent in mr3e, the only other member of the m-1 branch of the M-superfamily whose structure is known. Interestingly, injection of tx3a into mice elicits an excitatory response similar to that of the m-2 branch peptide mr3a, even though the conotoxins have different disulfide connectivity patterns. 


\section{INTRODUCTION}

Cone snails are a class of predatory marine snail, which inject a potent nerve toxin into their prey by way of a disposable hollow tooth. All of the approximately 500 members of the genus Conus are venomous hunters of fish, worms, or snails (1). Cone snail venom is typically composed of 40 to 200 small peptides which range in size from 10 to 40 amino acids (2). The great diversity and specificity of Conus toxins, termed conotoxins, have been attributed to intense evolutionary pressures. The venom serves as a defense against predators and in some cases, allows the slow moving snail to hunt rapidly moving prey (3).

It is the diversity, specificity and simplicity of conotoxins that contribute to their usefulness as receptor probes. Conotoxins can inhibit or induce muscle contraction in mice, block sodium, potassium or calcium channels, influence glutamate receptor binding, or cause behavioral changes in mice or other animals (4). The specificity shown by individual conotoxins provides the potential to isolate individual receptor types as well as to determine the essential elements for receptor-to-ligand binding (5).

Three-dimensional solution structures of conotoxins determined by NMR spectroscopy have served as models for structure/function relationships. To date, structures for approximately one hundred seven Conus peptides have been determined (6). The most studied of these peptides, the $\alpha$-conotoxins, selectively bind to specific subunits of the nicotinic acetylcholine receptor (nAChR) (7-13). These studies have contributed to an understanding of how nAChRs function and to the development of compounds that specifically target individual receptor types. The $\alpha$-conotoxins also demonstrate the potential of conotoxins in general to serve as potent and selective probes of closely related receptor types within the human body (14). 
Conotoxins of a particular family generally have the same arrangement of cysteine residues in their primary sequence, the same cystine pattern, and cause similar physiological effects in test animals, indicating that they target common receptor types. In contrast, the Msuperfamily, which is characterized by the three loop CC-C-C-CC cysteine arrangement, exhibits at least three distinct cystine patterns and a diversity of physiological effects in test animals. The superfamily consists of four branches, $\mathrm{m}-1, \mathrm{~m}-2, \mathrm{~m}-3$ and $\mathrm{m}-4$, defined by the number of residues between C4 and C5 (i.e. loop 3) (15). The diversity of peptides exemplified in this superfamily is thought to enhance the cone snail's ability to survive. For example the m-4 branch $\mu-, \psi-$, and $\kappa \mathrm{M}$-conotoxins with the same disulfide connectivity have a diverse set of molecular targets $\left(\mathrm{Na}^{+}\right.$channel, nicotinic acetylcholine receptor and $\mathrm{K}^{+}$channel respectively) (15).

There is considerable structural diversity among the M-superfamily conotoxins. Members of the m-1, m-2, and m-3 branches are smaller (12-19 AA) and contain different disulfide connectivities than those observed for the $\mathrm{m}-4$ branch peptides (22-24 AA). The m-1 branch peptides mr3e and tx3a have $\mathrm{C} 1-\mathrm{C} 5, \mathrm{C} 2-\mathrm{C} 4$, and $\mathrm{C} 3-\mathrm{C} 6$ connectivity patterns (16). Other disulfide connectivities within the M-superfamily are $\mathrm{C} 1-\mathrm{C} 6, \mathrm{C} 2-\mathrm{C} 4, \mathrm{C} 3-\mathrm{C} 5$ for the $\mathrm{m}-2$ branch, and $\mathrm{C} 1-\mathrm{C} 4, \mathrm{C} 2-\mathrm{C} 5, \mathrm{C} 3-\mathrm{C} 6$ for the $\mathrm{m}-4$ branch (Figure 1). While the receptors targeted by the $\mathrm{m}-$ 4 branch peptides are well-established, those for the $\mathrm{m}-1, \mathrm{~m}-2$, and $\mathrm{m}-3$ branch peptides have not been determined. Members of the M-superfamily peptides appear to be very abundant in cone snail venom and presumably are important for survival of the mollusks. The lack of physiological data for $\mathrm{m}-1, \mathrm{~m}-2$, and $\mathrm{m}-3$ branch peptides has apparently discouraged the widespread pursuit of their three-dimensional structures. Currently structures are only available for the m-1 branch peptide mr3e and the m-2 branch peptide mr3a. No representative structures 
have been reported for an m-3 branch peptide (17-18). In contrast, there are several representative structures in the literature for the $\mathrm{m}-4$ branch peptides, whose receptor targets have been determined (19-22).

\section{Figure 1}

Interest in tx3a, an m-1 branch conotoxin, arose because members of the M-superfamily appear to be present in every Conus species tested to date and the m-1, m-2, and m-3 conotoxins belong to a structurally and pharmacologically distinct group within the M-superfamily that has not been well-characterized. Physiologically tx3a causes hyperactivity in mice upon intracerebral injection at low doses ( $\sim 2$ nmoles $)$, which wears off after only a few minutes, and violent seizures followed by death at high doses ( $\sim 10$ nmoles $)$. The toxin is not active in fish upon intraperitoneal injection. Although the tx3a target receptor is undefined, the observation that it elicits such dramatic effects in mice at nanomolar quantities, yet does not affect fish, indicates that the peptide may be selective for certain receptor types. These physiological effects are similar to those reported for the $\mathrm{m}-2$ conotoxin mr3a (15). We now report the solution structure of conotoxin tx $3 \mathrm{a}$, which represents the second example of an m-1 branch peptide of the M-superfamily to be characterized by $2 \mathrm{D}^{1} \mathrm{H}$ NMR.

\section{Materials and Methods}

Preparation of tx3a. NMR samples were prepared at a concentration of approximately $4.2 \mathrm{mM}$ in either $100 \% \mathrm{D}_{2} \mathrm{O}$ (Cambridge Isotope Laboratories, Inc. Andover, MA) or 9:1 (v/v) $\mathrm{H}_{2} \mathrm{O} / \mathrm{D}_{2} \mathrm{O}$ with $0.01 \%$ TFA, $\mathrm{pH}$ 4.0. Three successive lyophilizations in $\mathrm{D}_{2} \mathrm{O}$ were performed to ensure complete exchange of labile protons. Two-dimensional ${ }^{1} \mathrm{H}$ NMR experiments and interpretation of spectra were based on established methods $(23,24)$.

NMR Spectroscopy. All NMR data were acquired at $11.75 \mathrm{~T}$ on a Varian INOVA $500 \mathrm{MHz}$ NMR spectrometer at $4.0^{\circ} \mathrm{C}$. Proton DQF-COSY (25), NOESY (26), and TOCSY (27) spectra 
in $\mathrm{D}_{2} \mathrm{O}$ were acquired with the transmitter set to $4.76 \mathrm{ppm}$ and a spectral window of $4500 \mathrm{~Hz}$, giving rise to FID's of 4096 complex points in the $\omega_{2}$ dimension. Spectra in $\mathrm{H}_{2} \mathrm{O}$ were acquired with the transmitter set at $4.8 \mathrm{ppm}$ and a spectral window of $6500 \mathrm{~Hz}$, giving rise to FID's of 4096 complex points in the $\omega_{2}$ dimension. Transmitter presaturation was applied at the solvent frequency to suppress the $\mathrm{H}_{2} \mathrm{O}$ resonance. Series of NOESY spectra were acquired with mixing times of 50, 100, and $200 \mathrm{~ms}$. A TOCSY spectrum was acquired with a mixing time of $200 \mathrm{~ms}$. Spectra were processed on a Silicon Graphics Indigo 2 and/or a Sun Spark 5 workstation using Varian VNMR software.

Restraint Set Generation. The ${ }^{3} J_{\mathrm{NH}-\alpha}$ values for $\mathrm{Cys}^{2}, \mathrm{Asp}^{5}, \mathrm{Val}^{6}, \mathrm{Cys}^{7}$, and $\mathrm{Cys}^{12}$ were extracted from a high resolution $1 \mathrm{D}{ }^{1} \mathrm{H}$ spectrum. Backbone dihedral phi angle restraints were set to -120 $+/-40^{\circ}$ for ${ }^{3} J_{\mathrm{NH}-\alpha}$ greater than $7.5 \mathrm{~Hz}$ and to $-65+/-25^{\circ}$ for a ${ }^{3} J_{\mathrm{NH}-\alpha}$ less than $5 \mathrm{~Hz}$. Inter- and intraproton distance ranges were derived from NOESY spectra recorded at $4{ }^{\circ} \mathrm{C}$ and mixing times of 50, 100, and $200 \mathrm{~ms}$. A plot of cross peak intensity versus mixing time allowed the initial slope of the NOE build-up to be calibrated. As a distance reference, the slope of the buildup for geminal protons was set to $1.8 \AA$. Restraints were set to $1.8-2.7,1.8-3.3$, and $1.8-5.0 \AA$ for high, medium, and low slopes of NOE intensity plotted against increasing mixing time,

This document is the unedited author's version of a submitted work that was subsequently accepted for publication in Biochemistry, (C2008 American Chemical Society after peer review. To access the final edited and published work see: DOI 10.1021/bi702388b

the times recorded were used for restraints (28).

Structure Calculations. One thousand initial structures generated from random starting conformations were input into the CYANA (V. 2.1) software (29). The distance geometry and gradient minimization calculations were performed to find the conformations which best modeled the 62 upper and 17 lower distance limits, the 5 phi angle, the 4 hydrogen bonds, and the 3 disulfide bonds consistent with the NMR data and the molecular backbone, respectively. A 
pseudo atom correction of $0.5 \AA$ was added to the upper bounds of restraints for methyl and methylene groups. The final set of 20 structures demonstrated an overall root-mean-square deviation among backbone atoms of $0.32+/-0.07 \AA$.

\section{RESULTS}

Assignment of Resonances. The complete ${ }^{1} \mathrm{H}$ resonance assignment for tx $3 \mathrm{a}$ was achieved using the method of Wüthrich (23) (See Table 1). A combination of DQF-COSY, NOESY, and TOCSY spectra acquired at $4{ }^{\circ} \mathrm{C}$ in both $9: 1(\mathrm{v} / \mathrm{v}) \mathrm{H}_{2} \mathrm{O} / \mathrm{D}_{2} \mathrm{O}$ and $100 \% \mathrm{D}_{2} \mathrm{O}$ were used to eliminate any ambiguities in assignment. Fourteen of the 15 amino acid spin systems for tx3a were identified in the "fingerprint" region of a $200 \mathrm{~ms}$ mixing time TOCSY spectrum. The remaining residue, Pro $^{10}$, lacks a resonance in this region of the spectrum and was identified later. Ten of the spin systems were confirmed in the "fingerprint" region of a DQF-COSY spectrum and assigned to $\mathrm{Cys}^{1}, \mathrm{Cys}^{2}, \mathrm{Ser}^{3}, \mathrm{Asp}^{5}, \mathrm{Val}^{6}, \mathrm{Cys}^{7}, \mathrm{Asp}^{8}, \mathrm{Ser}^{11}, \mathrm{Cys}^{12}$ and $\mathrm{Thr}^{13}$. Verification of $\alpha$ - and $\beta$-proton resonances and the location of the Pro ${ }^{10}$ spin system were extracted from TOCSY and DQF-COSY spectra acquired in $\mathrm{D}_{2} \mathrm{O}$. A complete and thorough mapping of all amino acid spin systems was accomplished in this manner.

\section{-Table 1-}

The assignment of spin systems to amino acids in the primary sequence of the peptide went as follows. The methyl region between 0.52 and $1.06 \mathrm{ppm}$ in the TOCSY spectrum acquired in $90 \% \mathrm{H}_{2} \mathrm{O}$ provided information needed to identify $\mathrm{Val}^{6}$ and $\mathrm{Thr}^{13}$. The two methyl resonances for $\mathrm{Val}^{6}$ at 0.55 and $0.52 \mathrm{ppm}$ were easily distinguished from the single methyl in $\mathrm{Thr}^{13}$ at $1.06 \mathrm{ppm}$. Diagnostic resonances were also seen for $\mathrm{His}^{9}, \operatorname{Trp}^{4}$ and $\operatorname{Pro}^{10}$. The ring protons of $\mathrm{His}^{9}$ and $\mathrm{Trp}^{4}$ were found in the TOCSY spectrum acquired in $\mathrm{D}_{2} \mathrm{O}$ between 6.65 and 9.86 ppm. $\operatorname{Trp}^{4}$ was distinguished from $\mathrm{His}^{9}$ by the proton on the nitrogen of the $\operatorname{Trp}^{4}$ indole 
ring. This indole proton, which resonated at $9.86 \mathrm{ppm}$, is unique to tryptophan. The spin system assigned to Pro ${ }^{10}$ originated at $4.13 \mathrm{ppm}$ in the TOCSY spectrum acquired in $\mathrm{D}_{2} \mathrm{O}$. The $\delta$ protons at 3.33 and $3.21 \mathrm{ppm}$ were helpful for assigning resonances for Pro ${ }^{10}$ because its $\alpha$ proton at $4.13 \mathrm{ppm}$ was within $0.04 \mathrm{ppm}$ of the $\alpha$-protons of $\mathrm{Cys}^{2}, \mathrm{Ser}^{3}, \mathrm{Cys}^{7}$ and $\mathrm{Asp}^{8}$. A complete trace of the $\operatorname{Pro}^{10}$ spin system was the only way to distinguish the amino acid from those with overlapping spin systems. The remaining amino acids, $\mathrm{Cys}^{1}, \mathrm{Cys}^{2}, \mathrm{Ser}^{3}, \mathrm{Asp}^{5}, \mathrm{Cys}^{7}$, $\mathrm{Asp}^{8}, \mathrm{Ser}^{11}, \mathrm{Cys}^{12}, \mathrm{Cys}^{14}$ and $\mathrm{Cys}^{15}$ all share the same AMX pattern and were sequentially assigned from the 200 ms NOESY spectrum by way of a "NOESY walk".

Sequential Assignments. The NOESY data were sufficient to observe proton-proton NOE's between the amide proton of one residue and the $\alpha$-proton of the preceding residue for Cys ${ }^{2}$, $\mathrm{Ser}^{3}$, and $\operatorname{Trp}^{4}, \mathrm{Cys}^{7}, \mathrm{Asp}^{8}$, and His ${ }^{9}$, and $\mathrm{Ser}^{11}, \mathrm{Cys}^{12}$, and $\mathrm{Thr}^{13}$.

Resonance assignments for $\mathrm{Val}^{6}$ and $\mathrm{Pro}^{10}$ came from their unique spin systems as discussed above. The remaining four residues, $\mathrm{Cys}^{1}, \mathrm{Asp}^{5}, \mathrm{Cys}^{14}$, and $\mathrm{Cys}^{15}$, were assigned based on sequential information combined with $\mathrm{H} \beta_{\mathrm{i}}$ to $\mathrm{HN}_{\mathrm{i}+1}$ cross peaks from the NOESY spectrum. Off-diagonal resonances were observed for the amide and $\alpha$-protons of $\mathrm{Cys}^{2}$ at 8.04 ppm and $4.14 \mathrm{ppm}$ to the $\beta$-protons of $\mathrm{Cys}^{1}$ at 2.62 and $2.26 \mathrm{ppm}$. Likewise, there was a weak NOE interaction between the amide proton of $\mathrm{Cys}^{1}$ at $8.09 \mathrm{ppm}$ and the $\beta$-protons of $\mathrm{Cys}^{14}$ at 2.95 and 2.75 ppm that helped to identify $\mathrm{Cys}^{14}$ and verify the assignment of Cys ${ }^{1}$. The assignment of $\mathrm{Cys}^{14}$ permitted the identification and assignment of $\mathrm{Cys}{ }^{15}$. There is an NOE between the amide proton of $\mathrm{Cys}^{14}$ at $8.82 \mathrm{ppm}$ and the $\beta$-protons of $\mathrm{Cys}^{15}$ at 2.14 and $2.01 \mathrm{ppm}$. Furthermore, there is a cross peak for the NOE between the amide proton of $\mathrm{Cys}^{15}$ and the $\beta$ -

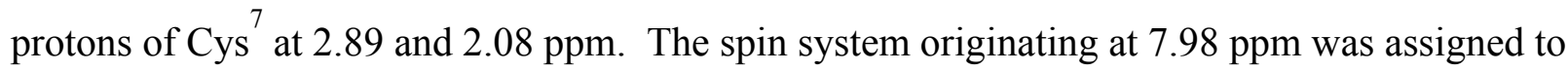
$\mathrm{Asp}^{5}$ by the process of elimination. 


\section{DISCUSSION}

Proton Assignments. The small size of conotoxin tx3a made it difficult to observe nuclear

Overhauser effects in NOESY spectra acquired at a temperature of $26^{\circ} \mathrm{C}$. A significant improvement in was seen at $4{ }^{\circ} \mathrm{C}$ although line widths were significantly broader. The spin systems were easier to resolve at $26{ }^{\circ} \mathrm{C}$ due to better spectral resolution and the NOESY spectra were more informative at $4{ }^{\circ} \mathrm{C}$ due to slower molecular tumbling. Thus, spectra acquired at both temperatures were used for assignments.

It was immediately apparent from spread of amide resonances that conotoxin tx $3 \mathrm{a}$ adopted a rigid conformation in solution. In general, random coil peptides have amide proton chemical shifts between 8.09 and $8.45 \mathrm{ppm}$, while those in conotoxin tx3a were between 7.15 and $8.90 \mathrm{ppm}$ (30). Similarly, the chemical shifts of $\alpha$-protons in random coils typically range from 4.4 to $4.8 \mathrm{ppm}$; while those in conotoxin tx3a resonated between 3.94 and $4.94 \mathrm{ppm}$. Thus, an ordered secondary structure was expected (31-35). The number of constraints per residue and a summary table of all restraints used for structure calculations are provided in Figure 2 and Table 2.

\section{-Figure 2-}

\section{-Table 2-}

Structure Analysis. The final set of 20 structures for conotoxin tx3a has a mean global backbone rmsd of $0.32 \pm 0.07 \AA$ (Figure 3). The backbone of the peptide is well-defined and conserved across all 15 amino acids.

\section{-Figure 3-}

The structure of conotoxin tx3a shows a "triple-turn" motif with turns between residues $\mathrm{Cys}^{1}$ and $\mathrm{Asp}^{5}, \mathrm{Val}^{6}$ and $\mathrm{His}^{9}$, and $\mathrm{Pro}^{10}$ and $\mathrm{Thr}^{13}$ (Figure 4). The N-terminal turn between 
residues $\mathrm{Cys}^{1}$ and $\mathrm{Asp}^{5}$ is a Type I $\beta$ turn held in place by a hydrogen bond between the carbonyl of $\mathrm{Ser}^{3}$ and the amide proton of $\mathrm{Asp}^{5}$ (distance $=2.23 \AA$ ). In $\beta$ turn nomenclature (36), $\mathrm{Cys}^{2}$ and $\operatorname{Trp}^{4}$ represent $i$ and $i+2$, respectively. $\operatorname{Trp}^{4}$ has its side chain indole ring pointing away from the core of the structure at the kink of the turn. This distinct protrusion significantly defines the surface of the peptide in this region. A second hydrogen bond between the amide proton of Cys ${ }^{1}$ and the carbonyl oxygen of $\mathrm{Val}^{6}$ further defines the first turn of the molecule. The section of the peptide surrounding $\operatorname{Trp}^{4}$ and $\mathrm{Asp}^{5}$ constitutes a hydrophilic patch on surface of the molecule. The side chain carboxylate of $\mathrm{Asp}^{5}$ and the carbonyl oxygen atoms of $\operatorname{Trp}^{4}$ and $\mathrm{Asp}^{5}$ point away from the interior of the peptide. This hydrophilic region is further established by "Turn 2."

The second turn occurs between residues $\mathrm{Val}^{6}$ and His ${ }^{9}$. This structural feature is a broad turn constrained by a hydrogen bond between the carbonyl of $\mathrm{Cys}^{7}$ and the amide proton of $\mathrm{His}^{9}$ (distance $=2.43 \AA$ ) and by the disulfide linkage of $\mathrm{Cys}^{7}$ and $\mathrm{Cys}^{15}$. The carboxylate of Asp ${ }^{8}$ is located at the kink in the turn and points away from the interior of the peptide to present a negatively charged region on the surface of the peptide. It deserves comment that the imidizole ring of $\mathrm{His}^{9}$ is also oriented away from the interior of the peptide. Thus, there is a region of positive character nearby the negatively charged $\mathrm{Asp}^{8}$ carboxylate. The surface created by the second turn of tx3a defines a hydrophilic side of the molecule. Thus, tx3a has a large hydrophilic face on the "Front" and "Side" regions shown in Figure 4. In contrast, the opposite side of the peptide is largely hydrophobic (see the "Back" portion of Figure 4) and corresponds to the location of the methyl and methylene groups of $\mathrm{Val}^{6}, \mathrm{Cys}^{7}, \mathrm{Cys}^{14}$, and $\mathrm{Cys}^{15}$. The only charged group on the surface of molecule in this region is the C-terminal carboxyl group of Cys $^{15}$. 
The third turn in the peptide is a Type III $\beta$ turn between residues Pro ${ }^{10}$ and $\mathrm{Thr}^{13}$. At the center of this turn is $\operatorname{Ser}^{11}(i+1)$. The turn is stabilized by the hydrogen bond between the amide proton of $\operatorname{Thr}^{13}(i+3)$ and the carbonyl oxygen $\operatorname{ser}^{11}(i+1)($ distance $=1.71 \AA)$. This region of the peptide defining the third turn appears significantly less hydrophilic on the surface than the first or second turn regions. Overall, the surface of tx3a is predominantly hydrophilic.

\section{-Figure 4-}

Comparison of $m-1$ branch peptides $t \times 3 a$ to $m r 3 e$. Conotoxin tx 3 a represents the second $m-1$ branch peptide of the M-superfamily for which a structure is now presented. The structure template for the m-1 branch conotoxins was first described for mr3e (17). The "triple-turn" structure we found for tx3a is substantially different than the "double-turn" motif reported for mr3e despite conserved cystine patterns in the two conotoxins. Differences in the backbone scaffolds of tx3a and mr3e appear to be due to a few key residues. mr3e has two consecutive glycines, $\mathrm{Gly}^{6}$ and $\mathrm{Gly}^{7}$, that do not appear in the tx 3 a sequence. These residues permit the sharp bend in turn 1 of the mr3e structure not seen in tx3a (37). Another difference is the number of residues between the cysteine groups. There are 12 residues between $\mathrm{C} 1$ and $\mathrm{C} 6$ in $\mathrm{mr} 3 \mathrm{e}$ and 3 residues between $\mathrm{C} 3$ and $\mathrm{C} 4$. In contrast, tx $3 \mathrm{a}$ has 13 residues between $\mathrm{C} 1$ and $\mathrm{C} 6$ and 4 residues between $\mathrm{C} 3$ and $\mathrm{C} 4$. Maintaining the same disulfide connectivity while changing the spacing of amino acid residues contributes to the observed structural differences between tx $3 \mathrm{a}$ and $\mathrm{mr} 3 \mathrm{e}$ (Figure 5).

\section{-Figure 5-}

tx3a has a more globular shape similar to that of the $m-2$ branch peptide mr3a, while mr3e has an irregular "flying bird" shape with several amino acid residues jutting out from the peptide backbone (17). The topology of tx3a more closely resembles that of mr3a, although the 
surface of tx3a is considerably more hydrophilic. For example, tx3a contains seven polar and charged residues, while mr3a contains only three $\left(\operatorname{Ser}^{5}, \operatorname{Arg}^{9}\right.$, and $\left.\mathrm{Hyp}^{14}\right)$. tx3a has a large hydrophilic region consisting of the carboxylate of $\mathrm{Asp}^{5}$, the carbonyl oxygen of $\mathrm{Cys}^{7}$, the carboxylate of $\mathrm{Asp}^{8}$, and the imidizole ring of $\mathrm{His}^{9}$ located primarily on the front face of the molecule. In spite of these differences, the two peptides exhibit similar excitatory physiological effects in mice and not toward fish. Thus, the "triple-turn" motif appears to be important for the excitatory behavior seen in mice.

It is well established that $\mathrm{m}-1, \mathrm{~m}-2$, and $\mathrm{m}-3$ peptides elicit a different symptomatology when injected into mice and fish than do their larger $\mathrm{m}-4$ counterparts. The $\mathrm{m}-4$ branch peptides, consisting of the $\mu-, \psi-$, and $\kappa \mathrm{M}$ toxins, are found primarily in fish-hunting Conus species. It is not surprising that the fish hunters require biological warfare agents that rapidly immobilize their fast moving prey. The $\mathrm{m}-4$ peptides are generally paralytic in nature. In contrast, the $\mathrm{m}-1, \mathrm{~m}-2$, and m-3 peptides are primarily found in the venoms of mollusk and worm-hunting cone snails. The physiological response that these smaller peptides elicit is excitatory. When injected with tx3a, mice become hyperactive in low doses and have seizures resulting in death in higher doses. $\mathrm{mr} 3 \mathrm{a}$ is known to cause barrel rolling seizures in mice. There are no reports of activity by $\mathrm{m}-1$, $\mathrm{m}-2$, or $\mathrm{m}-3$ conotoxins in fish. Although experiments have not been conducted with snails or worms, it is possible that exciting a snail or worm prey is advantageous by driving the "feast" from its protective habitat. Although the receptors for these peptides are not known, it is clear that they are active in a distinctive manner from their m-4 counterparts and the topology generated by the "triple-turn" motif seen in tx3a and mr3a is important for their observed activities. The role of the "triple-turn" scaffold in the interaction between tx3a, mr3a, and their target receptors will not be completely understood until their receptors are identified. 


\section{ACKNOWLEDGEMENTS}

We would like to thank Professor Baldomero M. Olivera, Dr. J. Michael McIntosh, Richard

Jacobsen, and Mikal-Anne Waters for assistance and advice on this project, Sean Ruettgers for technical support. 


\section{REFERENCES}

1. Kohn, A. J., Saunders, P. R., Wiener, S. (1960) Preliminary studies on the venom of the marine snail Conus, Annals of the New York Academy of Sciences 90, 706-725.

2. Myers, R. A., Cruz, L. J., Riviera, J. E., and Olivera, B. M. (1993) Conus peptides as chemical probes for receptors and ion channels, Chem. Rev. 93, 1923-1936.

3. Olivera, B. M., Rivier, J., Clark, C., Ramilo, C. A., Corpuz, G. P., Abogadie, F. C., Mena, E. E., Woodward, S. R., Hillyard, D. R., Cruz, L. J. (1990) Diversity of Conus neuropeptides, Science 249, 257-263.

4. Olivera, B. M., Gray, W. R., Zeikus, R., McIntosh, J. M., Varga, J., Rivier, J., de Santos, V., and Cruz, L. J. (1985) Peptide neurotoxins from fish-hunting cone snails, Science 230, 13381343.

5. Hann, R. M., Pagán, O., and Eterovic, V. A. (1994) The $\alpha$-conotoxins GI and MI distinguish between the nicotinic acetylcholine receptor agonist sites while SI does not, Biochemistry 33, 14058-14063.

6. RCSB Protein Data Base. http://www.rcsb.org/pdb/advSearch.do. Search Term: conotoxin (accessed November 2, 2007).

7. Chi, S., Kim, D., Olivera, B. M., McIntosh, J. M., and Han, K. (2004) Solution conformation of $\alpha$-conotoxin GIC, a novel potent antagonist of $\alpha 3 \beta 2$ nicotinic acetylcholine receptors, Biochem. J. 380, 347-352.

8. Everhart, D., Cartier, G. E., Malhotra, A., Gomes, A. V., McIntosh, J. M., and Luetje, C. W. (2004) Determinants of potency on $\alpha$-conotoxin MII, a peptide antagonist of neuronal nicotinic receptors, Biochemistry 43, 2732-2737.

9. McIntosh, J. M., Azam, L., Staheli, S., Dowell, C., Lindstrom, J. M., Kuryatov, A., Garrett, J. E., Marks, M. J., and Whiteaker, P. (2004) Analogs of $\alpha$-conotoxin MII are selective for $\alpha 6-$ containing nicotinic acetylcholine receptors, Mol. Pharmacol. 65, 944-952.

10. Loughnan, M. L. and Alewood, P. F. (2004) Physico-chemical characterization and synthesis of neuronally active $\alpha$-conotoxins, Eur. J. Biochem. 271, 2294-2304.

11. Nicke, A., Wonnacott, S., and Lewis, R. J. (2004) $\alpha$-Conotoxins as tools for the elucidation of structure and function of neuronal nicotinic acetylcholine receptor subtypes, Eur. $J$. Biochem. 271, 2305-2319.

12. Millard, E. L., Daly, N. L., and Craik, D. J. (2004) Structure-activity relationship of $\alpha$ conotoxins targeting neuronal nicotinic acetylcholine receptors, Eur. J. Biochem. 271, 23202326. 
13. Al-Sabi, A., Lennartz, D., Ferber, M., Gulyas, J., Rivier, J.E., Olivera, B.M., Carlomagno, T. and Terlau, H. (2004) $\mathrm{kM}$-Conotoxin RIIIK, structure and function novelty in a $\mathrm{K}^{+}$channel antagonist, Biochemistry 43, 8625-8635.

14. Bordia, T., Grady, S. R., McIntosh, J. M., and Quik, M. (2007) Nigrostriatal damage preferentially decreases a subpopulation of $\alpha 6 \beta 2 \mathrm{nAChRs}$ in mouse, monkey, and Parkinson's disease striatum, Mol. Pharm. 72, 52-61.

15. Corpuz, G. P., Jacobsen, R. B., Jimenez, E. C., Watkins, M., Walker, C., Colledge, C., Garrett, J. E., McDougal, O., Li, W., Gray, W. R., Hillyard, D. R., Rivier, J., McIntosh, J. M., Cruz, L. J., and Olivera, B. M. (2005) Definition of the M-conotoxin superfamily: characterization of novel peptides from molluscivorous Conus venoms, Biochemistry 44, 8176-8186.

16. Han, Y., Wang, Q., Jiang, H., Liu, L., Xiao, C., Yuan, D., Shao, X., Dai, Q., Cheng, J., and Chi, C. (2006) Characterization of novel M-superfamily conotoxins with new disulfide linkage, The FEBS Journal 273, 4972-4982.

17. Du, W., Han, Y., Huang, F., Li, J., Chi, C., Fang, W. (2007) Solution structure of an m-1 conotoxin with a novel disulfide linkage, The FEBS Journal 274, 2596-2602.

18. McDougal, O. M. and Poulter C. D. (2004) Three-dimensional structure of the mini-M conotoxin mr3a, Biochemistry, 43, 425-429.

19. Ott, K., Becker, S., Gordon, R. D., and Rüterjans, H. (1991) Solution structure of $\mu-$ conotoxin GIIIA analyzed by 2D-NMR and distance geometry calculations, FEBS Lett. 278, 160-166.

20. Hill, J.M., Alewood, P.F., and Craik, D.J. (1996) Three-dimensional solution structure of $\mu$ conotoxin GIIIB, a specific blocker of skeletal muscle sodium channels, Biochemistry 35, 8824-8835.

21. Van Wagoner, R. M. and Ireland, C. M. (2003) An improved solution structure for $\psi-$ conotoxin PIIIE, Biochemistry 42, 6347-6352.

22. Van Wagoner, R. M., Jacobsen, R. B., Olivera, B. M., and Ireland, C. M. (2003) Characterization and three-dimensional structure determination of $\psi$-conotoxin PIIIF, a novel noncompetitive antagonist of nicotinic acetylcholine receptors, Biochemistry 42, 6353-6362.

23. Wüthrich, K. (1986) NMR of Proteins and Nucleic Acids, Wiley: New York.

24. Bax, A. (1989) Two-dimensional NMR and protein structure, Annu. Rev. Biochem. 58, 223256. 
25. Rance, M., Sørensen, O.W., Bodenhausen, G., Wagner, G., Ernst, R. R., and Wüthrich, K. (1983) Improved spectral resolution in COSY proton NMR spectra of proteins via double quantum filtering, Biochem. Biophys. Res. Commun. 117, 479-485.

26. Jeener, J., Meier, B. H., Bachmann, P., and Ernst, R. R. (1979) Investigation of exchange processes by two-dimensional NMR spectroscopy, J. Chem. Phys. 71, 4546-4553.

27. Braunschweiler, L., and Ernst, R. R. (1983)Coherence transfer by isotropic mixing: application to proton correlation spectroscopy, J. Magn. Reson. 53, 521-528.

28. Keepers, J. W., and James, T. L. (1984) A theoretical study of distance determinations for NMR. Two-dimensional nuclear Overhauser effect spectra, J. Magn. Reson. 57, 404-426.

29. Güntert, P., Mumenthaler, C. \& Wüthrich, K. (1997) Torsion angle dynamics for NMR structure calculation with the new program DYANA, J. Mol. Biol. 273, 283-298.

30. Bundi, A., and Wüthrich, K. (1979) Proton NMR parameters of the common amino acid residues measured in aqueous solutions of the linear tetrapeptides H-Gly-Gly-X-L-Ala-OH, Biopolymers 18, 285-297.

31. Wishart, D. S., Sykes, B. D., and Richards, F. M. (1991) Relationship between nuclear magnetic resonance chemical shift and protein secondary structure, J. Mol. Biol. 222, 311333.

32. Wishart, D. S., Sykes, B. D., and Richards, F. M. (1991) Simple techniques for the quantification of protein secondary structure by proton NMR spectroscopy, FEBS Lett. 293, 72-80.

33. Wishart, D. S., Sykes, B. D., and Richards, F. M. (1992) The chemical shift index: a fast and simple method for the assignment of protein secondary structure through NMR spectroscopy, Biochemistry 31, 1647-1651.

34. Wishart, D. S., Bigam, C. G., Holm, A., Hodges, R. S., and Sykes, B. D. (1995) ${ }^{1}$ H, ${ }^{13}$ C, and ${ }^{15} \mathrm{~N}$ random coil NMR chemical shifts of the common amino acids. I. Investigations of nearest-neighbor effects, J. Biomol. NMR 5, 67-81.

35. Volkman, B. F., Nohaile, M. J., Amy, N. K., Kustu, S., and Wemmer, D. E. (1995) Threedimensional solution structure of the N-terminal receiver domain of NTRC, Biochemistry 34, 1413-1424.

36. Rose, G. D., Gierasch, L. M., and Smith, J. A. (1985) Turns in peptides and proteins, Adv. Protein Chem. 37, 1-109.

37. Voet, D. and Voet, J. G. (2004) Biochemistry. United States of America: John Wiley \& Sons, Inc. p.222-223. 
TABLES

\begin{tabular}{|c|c|c|c|c|}
\hline Residue HN & & $\alpha$ & $\beta$ & Other \\
\hline Cys 1 & 8.09 & 4.19 & $2.62,2.26$ & \\
\hline Cys 2 & 8.04 & 4.14 & $3.34,3.20$ & \\
\hline Ser 3 & 8.70 & 4.07 & $3.66,3.66$ & \\
\hline $\operatorname{Trp} 4$ & 8.45 & 3.94 & $3.09,2.97$ & $\begin{array}{l}2 \mathrm{H} 7.10 \\
4 \mathrm{H} 7.41 \\
5 \mathrm{H} 6.65 \\
6 \mathrm{H} 7.00 \\
7 \mathrm{H} 7.20 \\
\mathrm{NH} 9.86\end{array}$ \\
\hline Asp 5 & 7.98 & 4.56 & $2.75,2.65$ & \\
\hline Val 6 & 7.45 & 4.30 & 1.84 & $\gamma 0.55,0.52$ \\
\hline Cys 7 & 7.26 & 4.17 & $2.89,2.08$ & \\
\hline Asp 8 & 8.61 & 4.10 & $3.68,3.68$ & \\
\hline His 9 & 8.37 & 4.02 & $3.08,3.00$ & $\begin{array}{l}2 \mathrm{H} 7.03 \\
4 \mathrm{H} 7.12 \\
\end{array}$ \\
\hline Pro 10 & & 4.13 & $2.05,1.95$ & $\begin{array}{l}\gamma 1.74,1.45 \\
\delta 3.33,3.21\end{array}$ \\
\hline Ser 11 & 7.38 & 4.26 & $2.86,2.51$ & \\
\hline Cys 12 & 7.15 & 4.50 & $2.59,2.32$ & \\
\hline Thr 13 & 8.90 & 4.04 & 3.99 & $\gamma 1.06$ \\
\hline Cys 14 & 8.82 & 4.90 & $2.95,2.75$ & \\
\hline Cys 15 & 8.88 & 4.94 & $2.14,2.01$ & \\
\hline
\end{tabular}

Table 1. Proton resonance assignments for conotoxin tx $3 \mathrm{a}$ at a temperature of $4{ }^{\circ} \mathrm{C}$.

\begin{tabular}{|l|r|l|l|r|}
\hline \multicolumn{1}{|c|}{ Distance Restraints } & & & \multicolumn{1}{c|}{ Dihedral Restraints } & \\
\hline Intraresidue & 4 & & Phi angle & 5 \\
\hline Sequential & 26 & & Hydrogen bond & 4 \\
\hline Medium & 22 & & Total 9 & \\
\hline Long & 48 & & & \\
\hline Total 100 & & & & \\
\hline & & & & \\
\hline & & & & \\
\hline
\end{tabular}

Table 2: Restraints used to determine the structure of tx3a. 


\section{FIGURE LEGENDS}

1. A summary of the four branches of the M-Superfamily containing the conserved CC-CC-CC cysteine pattern with divergent cystine connectivity.

2. A distribution of distance constraints as a function of their residue number used for the structure determination of conotoxin tx3a. The white areas represent intraresidual constraints, light gray areas symbolize sequential constraints, dark gray areas show medium-range NOE's $\left(\mathrm{d}_{\mathrm{ij}} \leq 5 \AA\right)$ and black areas depict long-range NOE's $\left(\mathrm{d}_{\mathrm{ij}} \geq 5 \AA\right)$.

3. An overlay of the backbone atoms of tx3a for the final 20 structures generated by CYANA.

4. Three-dimensional structures of tx3a. Shown is the backbone structure identifying each of the turns (top left), turn 1 from $\mathrm{Cys}^{1}$ to $\mathrm{Asp}^{5}$ (green), turn 2 between $\mathrm{Val}^{6}$ and His ${ }^{9}$ (red), and turn 3 between Pro ${ }^{10}$ and Thr $^{13}$ (blue). The disulfide bonds are shown in yellow with the cystine residues numbered. Also shown are the front, side and back views of the surface of the peptide. Blue regions represent electropositive surfaces, red regions are electronegative surfaces, and white/faintly colored regions are hydrophobic/nonpolar surfaces.

5. Comparison between two $m-1$ branch peptides, tx $3 \mathrm{a}$ and $\mathrm{mr} 3 \mathrm{e}$, and $\mathrm{m}-2$ branch peptide, mr3a. Scaffold structures of tx3a, mr3e, and mr3a are labeled A, B, and C, respectively. Frontal surface structures of tx3a (D), mr3e (E), and mr3a (F), showing the "flying bird" depiction of mr3e and the "plucked chicken" representation for tx3a and mr3a. Blue regions represent electropositive surfaces, red regions are electronegative surfaces, and white/faintly colored regions are hydrophobic/nonpolar surfaces. 


\section{FIGURES}

Figure 1

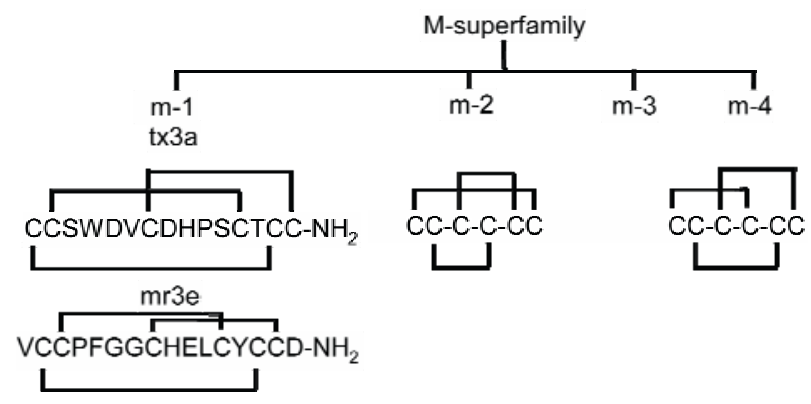

Figure 2

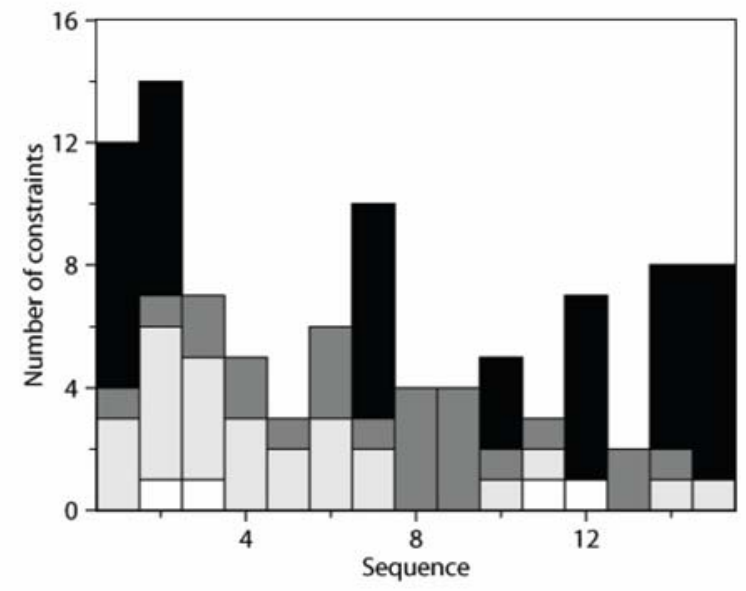

Figure 3

c

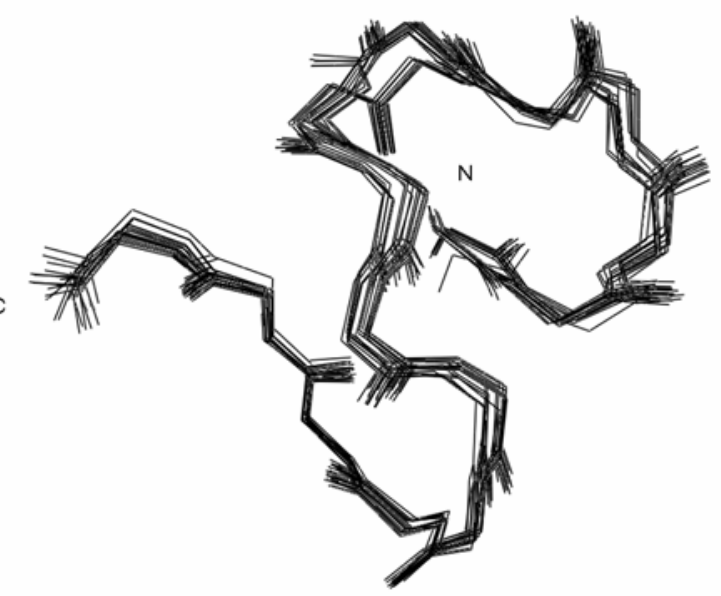


Figure 4

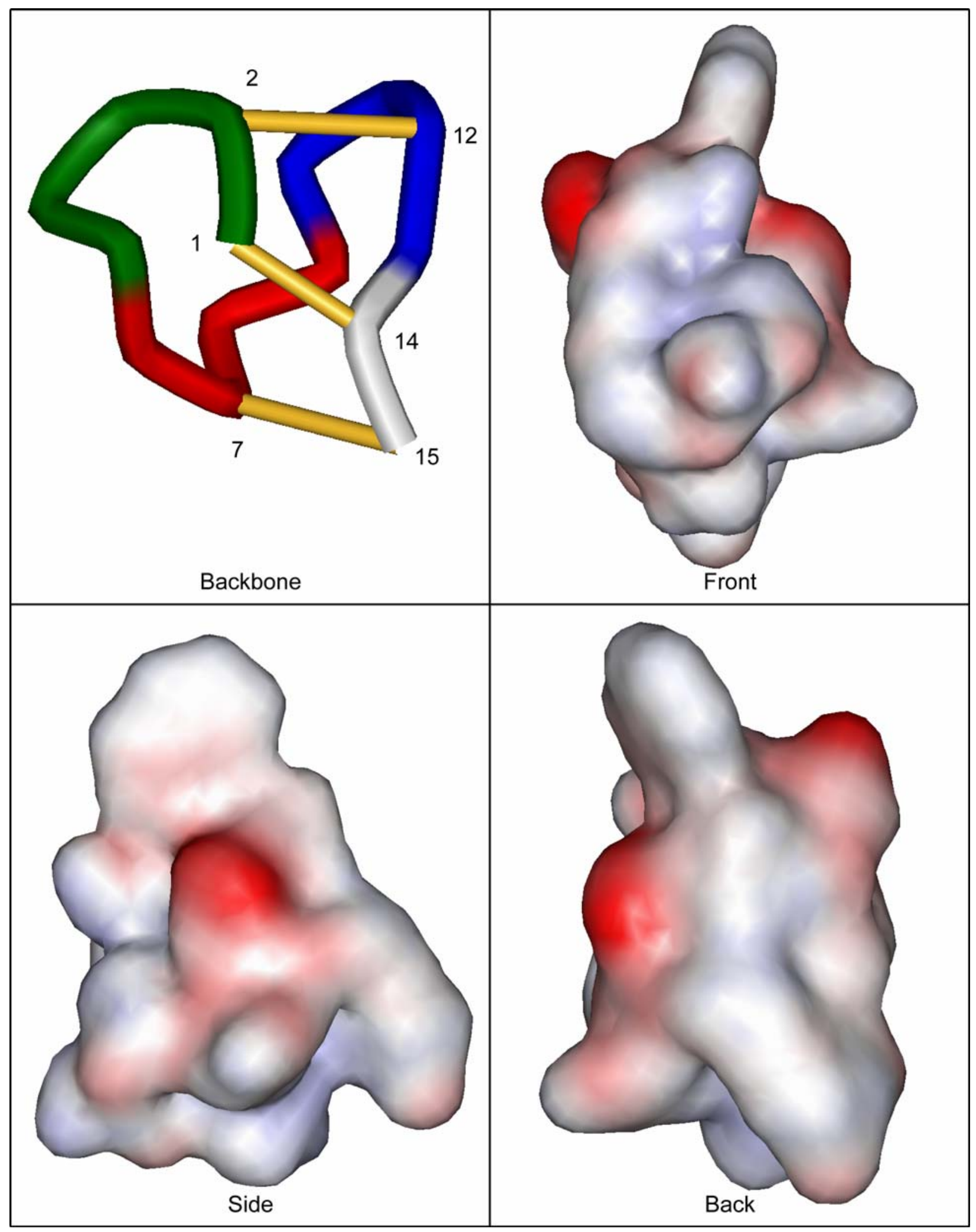


Figure 5

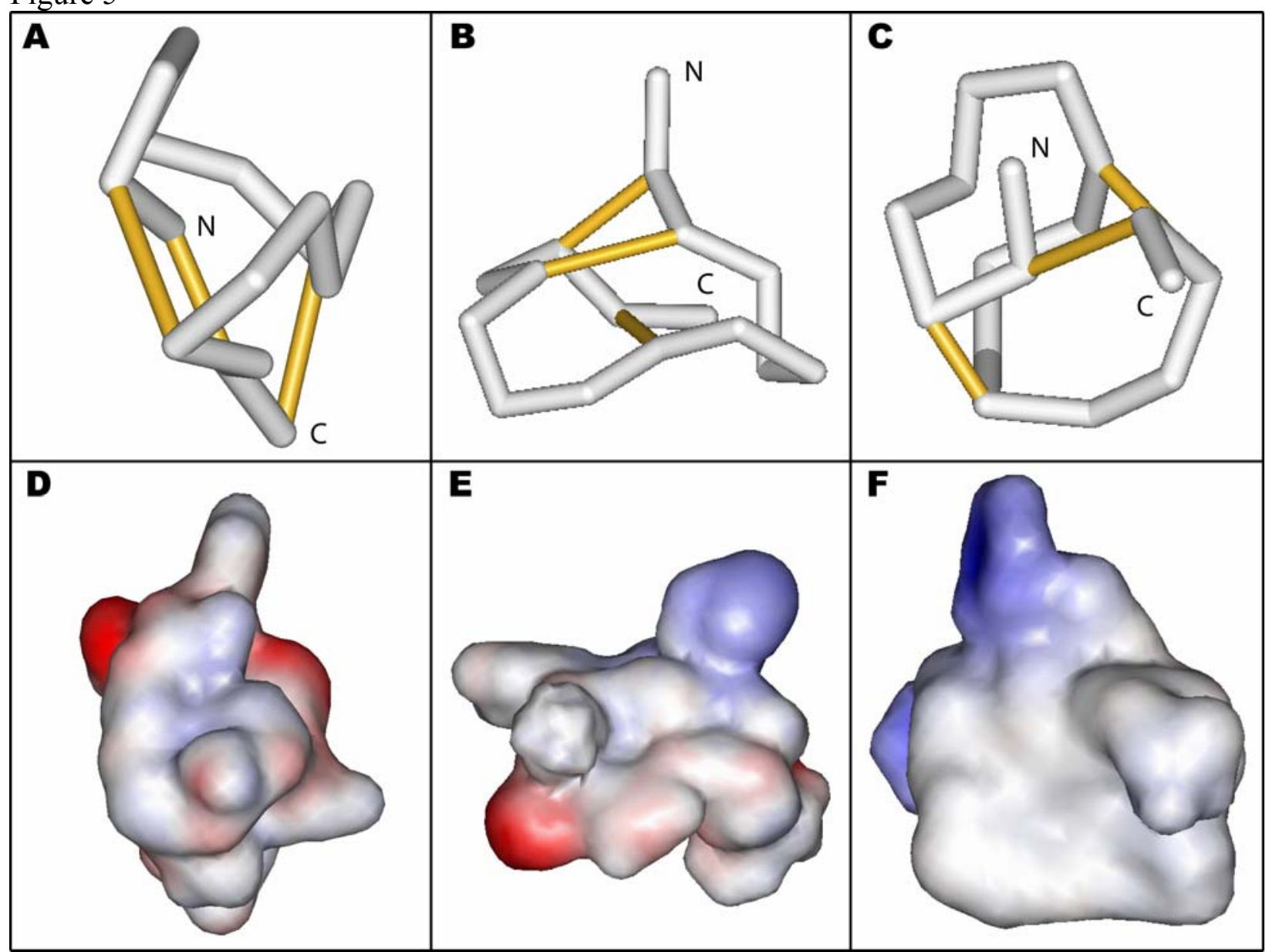


FOR TABLE OF CONTENTS USE ONLY

\section{Three-Dimensional Structure of Conotoxin tx3a: A m-1 Branch Peptide of the M-Superfamily ${ }^{\dagger}$}

Owen M. McDougal ${ }^{\ddagger *}$, Matthew W. Turner ${ }^{\ddagger}$, Andrew J. Ormond ${ }^{\ddagger}$, and C. Dale Poulter ${ }^{\S}$

${ }^{*}$ Department of Chemistry and Biochemistry, Boise State University, Boise, Idaho 83725

${ }^{\S}$ Department of Chemistry, University of Utah, Salt Lake City, Utah 84112

${ }^{*}$ Corresponding author

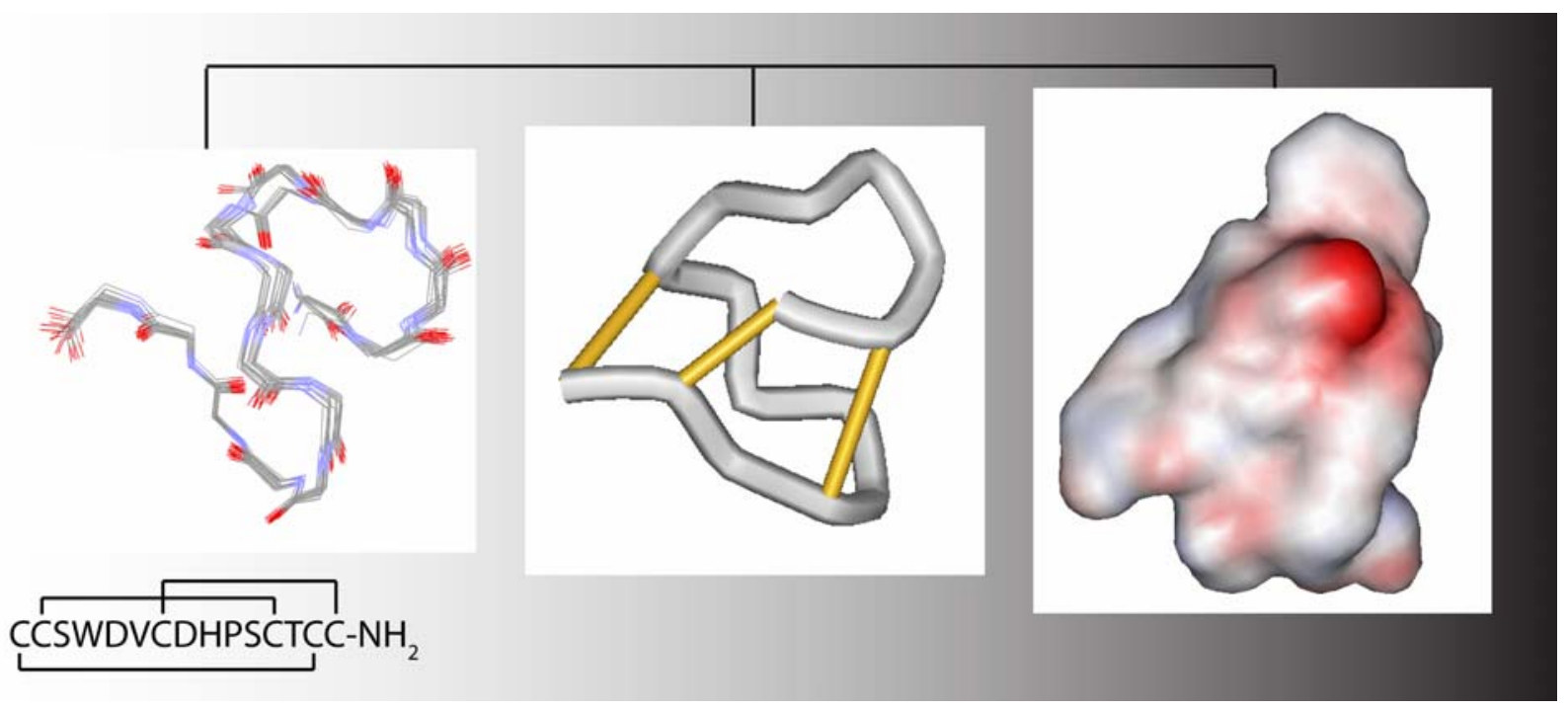

